\title{
Delivering Growth Factors through a Polymeric Scaffold to Cell Cultures Containing both Nucleus Pulposus and Annulus Fibrosus
}

\author{
Yener AKYUVA ${ }^{1}$, Necati KAPLAN² ${ }^{2}$, Ibrahim YILMAZ³, Hanefi OZBEK ${ }^{3}$, Duygu YASAR SIRIN ${ }^{4}$, \\ Numan KARAASLAN ${ }^{5}$, Olcay GULER ${ }^{6}$, Ozkan ATES ${ }^{7}$
}

\begin{abstract}
${ }^{1}$ Gaziosmanpasa Taksim Training and Research Hospital, Neurosurgery Clinic, Istanbul, Turkey 2Istanbul Rumeli University, Department of Neurosurgery, Istanbul, Turkey ${ }^{3}$ Istanbul Medipol University, School of Medicine, Department of Pharmacology, Istanbul, Turkey ${ }^{4}$ Namik Kemal University, Department of Molecular Biology and Genetics, Tekirdag, Turkey ${ }^{5}$ Namik Kemal University, Department of Neurosurgery, Tekirdag, Turkey ${ }^{6}$ Bahcelievler Medical Park Hospital, Orthopaedics and Traumatology Clinic, Istanbul, Turkey ${ }^{7}$ Istanbul Esenyurt University, Esencan Hospital, Neurosurgery Clinic, Istanbul, Turkey
\end{abstract}

Corresponding author: Yener AKYUVA yenerakyuva@hotmail.com

\section{ABSTRACT}

AIM: To design a novel, polyvinyl alcohol (PVA)-based polymeric scaffold that permits the controlled release of insulin-like growth factor 1 (IGF-1)/bone morphogenetic protein (BMP)-2 following intervertebral disc administration.

MATERIAL and METHODS: The drug delivery system was composed of two different solutions that formed a scaffold within seconds of coming into contact with each other. Swelling, $\mathrm{pH}$, and temperature tests and analysis of the controlled release of growth factors (GFs) from this system were performed. The release kinetics of the GFs were determined through enzyme-linked immunosorbent assay (ELISA). Cell proliferation and viability were monitored with microscopy and analyzed using an MTT assay and acridine orange/propidium iodide (AO/PI) staining. Chondroadherin (CHAD), hypoxia inducible factor-1 alpha (HIF-1a), and collagen type II (COL2A1) gene expressions were determined with quantitative real-time polymerase chain reaction (qRT-PCR) analysis to show the effects of IGF-1/BMP-2 administration on annulus fibrosus cell (AFC)/nucleus pulposus cell (NPC) cultures. For the statistical evaluation of the obtained data, experimental groups were compared with a post hoc Tukey's test following an analysis of variance.

RESULTS: The scaffold allowed for the controlled release of IGF-1 and BMP-2 in different time intervals. It was observed that as the application time increased, the number of cells and the degree of extracellular matrix development increased in AFC/NPC cultures. AO/PI staining and an MTT analysis showed that cells retained their specific morphology and continued to proliferate. It was observed that HIF-1a and CHAD expression increased in a time-dependent manner, and no COL2A1 expression in the AFC/ NPC cultures was observed.

CONCLUSION: The designed scaffold may be used as an alternative method for intervertebral disc administration of GFs after further in vivo studies. Such prototype scaffolds may be an innovative technology in targeted drug therapies after reconstructive neurosurgical interventions.

KEYWORDS: Annulus fibrosus, BMP-2, IGF-1, Intervertebral disc disease, Nucleus pulposus, Polymeric scaffold, Primary cell culture

Yener AKYUVA (D): 0000-0001-8171-5929 Necati KAPLAN (1): 0000-0001-5672-0566 Ibrahim YILMAZ (1) : 0000-0003-2003-6337
Olcay GULER (1) : 0000-0001-8849-8680 Ozkan ATES (D) : 0000-0002-2985-518X 


\section{INTRODUCTION}

I ntervertebral disc degeneration results in a reduction in quality of life. In particular, the nucleus pulposus (NP) and annulus fibrosus (AF) are damaged in intervertebral disc degeneration (1). Vascular feeding of almost all NP tissues is obliterated when people are in their early 30 s, so this region is subsequently fed by means of environmental diffusion (33). Accordingly, the water content in the NP decreases, and the natural elasticity of the disc is deformed. Thereafter, physical forces are transmitted through the body as nonlinear and asymmetrical (22).

Posterolateral, central, and foraminal herniation (or, rarely, extraforaminal herniation) occurs after the annulus becomes fragile, and the NP is fragmentized following water loss, which results in vertebral degeneration (18). Steroid treatment and/ or myorelaxants combined with non-steroidal, analgesic, anti-inflammatory drugs are among the most advanced conservative treatments (38). Rest, appropriate exercise, and physical rehabilitation are also recommended $(24,42)$. In patients with no apparent neuromotor deficits, facets and/ or epidural injections and intradiscal interferences can be applied as a second stage (10). Surgery has gained popularity in treating degenerative disc diseases, mechanical instability, and spondylolisthesis diseases. In addition to ordinary discectomy, posterior fusion surgery may be applied through an anterior-posterolateral interbody cage and/or a posterior transpedicular screw rod system (37).

However, due to routine anesthesia and surgery, there are some risks in these surgical applications. To illustrate, surgical operations can result in nerve root or dura damage, bleeding, or failure in hernia excision, or the surgery can be non-effective due to a faulty stage. Furthermore, other complications can occur, such as postoperative fibrosis, infection, recurrence, implant shifts, or damage in the nerve root due to faulty localization (47). Moreover, the results of treatments have not been promising despite conservative surgical attempts in neurosurgery (28).

Disc herniation, spinal stenosis, or segmental instability may occur in degenerative intervertebral discs (IVDs) from old age or interaction with traumatic, mechanical, genetic, metabolic, and biochemical factors. Considering the fact that NP cells (NPCs) and AF cells (AFCs) that are sufficient in number and quality are needed, promising cellular treatments are in demand (8).

Recent research has been oriented toward customized cellular studies that target the regeneration of the damaged tissues. As with all branches of medicine, neurosurgery seeks a solution regarding how undamaged tissues can be preserved and how damaged tissues can be repaired biologically. Present pharmacogenomic studies aim to treat damaged tissues without side effect profiles $(11-13,16,19-21,25,35,51,52)$.

Growth factors (GFs) are included in these studies on cellular treatment and pharmaceutical technology that target intervertebral disc degeneration (15). However, it is known that the half-lives of peptide or growth hormones, such as insulin-like growth factor 1 (IGF-1) and bone morphogenetic protein (BMP)-2, range from 10 seconds to 2 minutes $(2,11,15,16,20,25,51,52)$.

The bioactivity of the proteins and peptides in regions where they are used directly without drug delivery is still topical $(6,16,21,51,52)$. For this reason, various scaffolds are used in these preparations and are locally applied in the target region to regenerate the damaged tissues $(6,15,25,52)$. In the literature, few studies on this subject have demonstrated the success of scaffold systems in regenerating damaged tissues.

The present study was one of the few in which IGF-1 and BMP-2 were embedded into a bilayer hydrogel. This scaffold is polymeric and biodegradable, and the GFs within it are controllably released. By this means, the hypothesis that the mostly affected AFCs and NPCs in IVD can be effectively regenerated was tested. The present study aimed to determine the possibility of reaching more promising results with this method in comparison with traditional clinical applications.

\section{MATERIAL and METHODS}

The researchers were blind as to whether the scaffold was used as well as to its content. With the purpose of minimizing faulty measurements, similar measurements were performed by the same researchers. All experiments were carried out three times. The study was carried out with the approval of the local ethics board. Informed consent was obtained from patients attending the Orthopedics and Traumatology Clinic and the Neurosurgery Clinic for use of their cells.

\section{Patient Selection and Eligible Criteria}

The designed PVA-based, polymeric scaffold was evaluated in terms of its rheological, morphological, and release kinetics. Cases with rheumatic and immunological diseases, acute renal failure, and/or chronic liver failure were excluded from the study along with pregnant women, children, and patients with malignancies. Moreover, patients who used drugs that might interact with the cytochrome p450 system enzyme CYP2A6 over the last four weeks were excluded as the interaction might have affected the enzyme levels. Patients taking rheumatic drugs, which are used in traditional treatment modalities for rheumatic diseases, were also excluded. In addition, patients using biological therapy agents, such as rituximab, etanercept, adalimumab, and abatacept, were not allowed to take part in the research $(12,13,16,19-21,51,52)$.

\section{Preparation of Polymeric Scaffolds with GFs and Pharmacokinetic Determination of Release Ratios through Physicochemical Analyses}

A mixture of sodium tetra borate and PVA-chitosan/starch (Sigma Chemical) was prepared in a 1:4 ratio in order to set bio fragmentation in motion. On the outer PVA-chitosan/ starch layer of the scaffold, BMP-2 (Gibco; Cat. \# 760828N) was added to the $1: 4$ solutions in doses of $100 \mathrm{ng} / \mathrm{mL}$ (2). On the inner PVA-chitosan/starch layer of the scaffold, $100 \mathrm{ng} / \mathrm{mL}$ of IGF-1 (Gibco; Cat. \# 74508690A) was embedded into the $1: 4$ solutions $(40)$. 
After both layers were prepared one by one, weak crosslinking was strengthened with the aid of sodium tetra borate and starch reagents in such a way as to enable a 21-day controlled release. A swelling test was performed to calculate the molecular weight between cross-links in the swollen scaffold (6). Hydrogel samples were broken into pieces (4.5 $\mathrm{mm}$ inner diameter, $1.5 \mathrm{~mm}$ thickness, $10 \mathrm{~mm}$ length) in order to calculate the swelling balance in ultra-pure water. A cold treatment was applied to these samples for 6 hours at $-20^{\circ} \mathrm{C}$. Afterward, they sat for another 6 hours at $37 \pm 0.5^{\circ} \mathrm{C}$. The dry weight of the samples was weighed and reported. These hydrogel samples were embedded for 240 minutes after they were taken from $25 \mathrm{ml}$ of ultra-pure water on the condition that filtration was used. While they were being embedded, they were taken out every 20 minutes. The surfaces of the samples were dried by blotting paper, and their weights were recorded. After calculating their swelling balance, their diameters were measured by means of a digital caliper. In this way, the dynamic weight index for swelling (i.e., the hydration rate) at the time the system would be embedded with IGF-1 and BMP-2 and delivering drugs was calculated using the equation

$$
[(\mathrm{W} 2-\mathrm{W} 1) /(\mathrm{W} 1)] \times 100
$$

where $W_{1}=$ indicates the initial dry weight, and $W_{2}=$ indicates the weight of swelled hydrogel particles $(6,25,52)$.

Release experiments were carried out in a PBS (phosphate buffer saline [PBS], $\mathrm{pH}=7.4$ ) solution. Absorbance changes during the release of embedded GFs were measured by an ultraviolet spectrophotometer at $37.4^{\circ} \mathrm{C}$ focused between 260 and $280 \mathrm{~nm}$. A PBS solution with $0.1 \%$ nitrogen and $0.9 \%$ isotonic sodium chloride was prepared and put into the mixture. The drug delivery system with embedded BMP2 and IGF-1 was kept in beakers for 8 days. Its layers were evaluated one by one, and the PBS solution in which it was suspended was changed every 12 hours. During the PBS change, viscous liquid samples were taken in 1-mm Eppendorf tubes and spectrophotometrically analyzed. The active and inactive ingredients in the PBS and its hydrogel content were measured, the results of which showed that the polymeric scaffold was devoid of additional content in hydrogel and PBS solutions. Afterward, the PBS solution in the beakers was measured. The number of released GFs could be measured because the polymeric scaffold was devoid of PBS and hydrogel content except BMP-2 and IGF-1. These data were used to prepare a time series graph against released GFs. The released amounts of BMP-2 and IGF-1 were subtracted from the initial amounts that had been loaded into hydrogel. Thus, it was possible to calculate the amount of BMP-2 and IGF-1 released and unreleased in the drug delivery system $(6,25,52)$. All samples were grouped according to their contents (Table I).

\section{Establishment of Primary Cultures}

The tissues used for the study groups were obtained from patients who had applied to clinics with complaints of lumbar pain with radicular symptoms. These symptoms and the examination findings included Laseque test positivity, sensory deficits, motor deficits, reflex changes, sphincter disturbances, and autonomic dysfunctions. After the patients were examined, those who decided to undergo lumbar disc hernia operations underwent magnetic resonance imaging (MRI). The tissues used in the study group had degenerated disc herniations. The degenerative nature of the disc tissue was confirmed by preoperative MRI examination. These hernias were extruded, migrated fragments that compressed the spinal cord or nerve root. Disc degeneration was graded using the Pfirrmann classification with the help of T2-weighted MRIs (14).

Table I: Experimental Design: Group ID, Sample Tissue, Application, and Duration of Application

\begin{tabular}{|c|c|c|c|c|}
\hline Group ID & & Sample $^{a}$ & Application $^{a}$ & $\begin{array}{l}\text { Duration of } \\
\text { application }\end{array}$ \\
\hline \multirow{3}{*}{ Group 1} & $A$ & \multirow{3}{*}{ dNPCs/AFCs } & \multirow{3}{*}{ GF $(-)$} & $\mathrm{Oh}$ \\
\hline & B & & & $7 \mathrm{~d}$ \\
\hline & C & & & $21 d$ \\
\hline \multirow{3}{*}{ Group 2} & $A$ & \multirow{3}{*}{ iNPCs/AFCs } & \multirow{3}{*}{ GF $(-)$} & $\mathrm{Oh}$ \\
\hline & $B$ & & & $7 \mathrm{~d}$ \\
\hline & $\mathrm{C}$ & & & $21 d$ \\
\hline \multirow{3}{*}{ Group 3} & A & \multirow{3}{*}{ dNPCs/AFCs } & \multirow{3}{*}{ GF (+) } & $\mathrm{Oh}$ \\
\hline & B & & & $7 d$ \\
\hline & $\mathrm{C}$ & & & $21 d$ \\
\hline \multirow{3}{*}{ Group 4} & A & \multirow{3}{*}{ iNPCs/AFCs } & \multirow{3}{*}{ GF (+) } & $\mathrm{Oh}$ \\
\hline & $\mathrm{B}$ & & & $7 \mathrm{~d}$ \\
\hline & C & & & $21 d$ \\
\hline \multirow{3}{*}{ Group 5} & A & \multirow{3}{*}{ dNPCs/AFCs } & \multirow{3}{*}{ GF (+)/Hyd } & $\mathrm{Oh}$ \\
\hline & $\mathrm{B}$ & & & $7 \mathrm{~d}$ \\
\hline & $\mathrm{C}$ & & & $21 \mathrm{~d}$ \\
\hline \multirow{3}{*}{ Group 6} & A & \multirow{3}{*}{ iNPCs/AFCs } & \multirow{3}{*}{ GF (+)/Hyd } & $\mathrm{Oh}$ \\
\hline & $\mathrm{B}$ & & & $7 \mathrm{~d}$ \\
\hline & $\mathrm{C}$ & & & $21 d$ \\
\hline \multirow{3}{*}{ Group 7} & A & \multirow{3}{*}{ dNPCs/AFCs } & \multirow{3}{*}{ Hyd } & $\mathrm{Oh}$ \\
\hline & $\mathrm{B}$ & & & $7 \mathrm{~d}$ \\
\hline & $\mathrm{C}$ & & & $21 d$ \\
\hline \multirow{3}{*}{ Group 8} & $A$ & \multirow{3}{*}{ iNPCs/AFCs } & \multirow{3}{*}{ Hyd } & $\mathrm{Oh}$ \\
\hline & $\mathrm{B}$ & & & $7 \mathrm{~d}$ \\
\hline & C & & & $21 d$ \\
\hline
\end{tabular}

${ }^{a}$ GF (-): Cell cultures without growth factor (ie, BMP-2, IGF-1) applied. GF (+): Cell cultures with growth factor (ie, BMP-2, IGF-1) applied. GF (-)/Hyd: Negative control, only hydrogel applied. GF (+)/Hyd: Growth factor (ie, BMP-2, IGF-1) embedded into hydrogel. dNPCs/AFCs: NPCs/AFCs cell culture obtained from degenerated tissue. iNPCs/ AFCs: NPCs/AFCs cell culture obtained from intact tissue. $\boldsymbol{h}$ : hours, d: days. 
Considering the modified classification system describing the morphology of herniations proposed by the International Society for the Study of the Lumbar Spine, three cases had migrated disc herniations, two cases had inter-ligament extrusion, two cases had under-ligament extrusion, and two cases had protrusion. There were nine sampled cases. Two cases were at the L3 and L4 levels, three were at the L3-L5 levels, and four were at the L5-S1 levels (Figure 1A-E).

Tissues from the cases ( $n=9$; average age: $41.72 \pm 15.24$ years, range: $26-57$ years) were resected during microdiscectomy. Then, to be used for NPC/AFC cultures, the tissues were taken into sterile falcon tubes containing penicillin-streptomycin. The disc and granulation tissues in the tubes were removed in the laboratory, where they were consecutively washed five times.

The cases for the control group ( $n=9)$ were chosen by considering their sex, age (average age: $40.18 \pm 15.32$ years, range: $25-58$ years), and body mass index, as the control group was intended to bear a resemblance to the work group. In addition, the cases were healthier and did not have degenerated discs. The population of primary cells was obtained from volunteers who had applied for emergency service because they had fallen from a great height or had spinal trauma $(n=15)$. After the cases with vertebrae fractures in the thoracolumbar/lumbar region and cases with spinal cord compression were included in the control group, primary cultures were prepared. The non-degenerative (intact) nature of the disc tissue was confirmed by preoperative MRI examination. Nine of these cases were included in the study. They had been planned to have partial or total corpectomies after lumbar MRI, yet their adjacent discs were found to be healthy after T2-weighted images (Figure 1F-J).

Tissues obtained from two different anatomical regions were put into falcon tubes containing $5 \%$ penicillin-streptomycin and Dulbecco Modified Eagle's Medium (DMEM) under appropriate conditions. Tissues in a laminar flow cabinet were washed with a sterile PBS solvent, and red blood cells were cleaned.

The samples were mechanically shaken. Type I ( $475 \mu \mathrm{g} / \mathrm{mL})$ and type II $(125 \mu \mathrm{g} / \mathrm{mL})$ collagenase Clostridium histolyticum enzymes that had been solubilized in Hanks' Balanced Salt Solution (HBSS) were added to the tissues. These tissues were then kept in an incubator overnight. The tissues that had been enzymatically digested were centrifuged at $4^{\circ} \mathrm{C}$ and 1,300 rpm for 10 minutes. The cell pellet at the bottom of the centrifuge was re-suspended using the culture medium that had been prepared with DMEM. After the samples were transferred to flasks, they were left to incubate for 72 hours. The degenerated and healthy samples in the NPCs/ AFCs obtained from humans were transferred into wells and fed for 21 days. Then, the cells were counted by means of a Neubauer chamber using Trypan blue dye. Afterward, they were divided in the following manner: $1.4 \times 10^{4} \mathrm{cells} /$ well in 96-well plates, $4.6 \times 10^{5}$ cells/well in 6 -well plates, and $4.6 \times$ $10^{6}$ cells in a $10-\mathrm{mm}$ petri plate. Lastly, they were incubated for 24 hours. A Transwell chamber was used to separate the polymeric scaffold and primary cell culture samples.

\section{Imaging with Inverted and Fluorescent Microscopy}

An inverted light microscope (Olympus, CKX41) was used to monitor cell cultures, and a fluorescent microscope (Leica, DM 2500) was used for an acridine orange/propidium iodide $(\mathrm{AO} / \mathrm{PI})$ analysis. Microphotographs of cell organization were obtained before and during the applications. The images were evaluated using the Cytovision Capture Station imaging program.

\section{Tests of Vitality and Proliferation}

A 3-(4,5-dimethyltiazol-2-yl)-2,5-diphenyltetrazolium bromide assay (MTT) was performed on the 1st, 7th, and 21st days (MTT Cell Proliferation Assay Cat. \# V-13154, Cell Biolabs Inc., USA), according to the manufacturer's instructions.

The MTT kit is based on the principle that blue formazan crystals are formed by means of dehydrogenase enzymes, which are in tetrazolium rings, and that formazan crystals do not form in dead cells. By means of a pipette gun, feedlots were removed on the $1^{\text {st }}, 7^{\text {th }}$, and $21^{\text {st }}$ days in a dark environment. The MTT, which was diluted in DMEM, was added into each well in a proportion of $300 \mu \mathrm{L}$. After the incubation, which took 170 minutes, dimethylsulfoxide was added to each well. Samples underwent ELISA and were assessed at $540 \mathrm{~nm}$ $(\mathrm{OD}=$ Optical Density). Living cell reproduction was calculated in percentages using the following equation $(6,11-13,15,19$ $21,25,35,52)$ :

Cell proliferation $=($ test OD $) /($ Control OD $) \times 100$

On the $1^{\text {st }}$ day, the number of living cells was accepted as $100 \%$. The number of living cells was then calculated on the $7^{\text {th }}$ and $21^{\text {st }}$ days. Whether there was a difference across groups in terms of proliferation was analyzed accordingly.

\section{Preparation and application of the AO/PI stain}

An AO/PI stain was prepared in a mixture of $10 \mathrm{~g} \mathrm{Na-EDTA,} 4$ $\mathrm{mg} \mathrm{PI}, 50 \mathrm{ml}$ fetal calf serum, and $4 \mathrm{mg} \mathrm{AO}$ (dissolved in $2 \mathrm{ml}$ of $99 \%$ ethanol). Then, sterile, distillated water was added to reach $200 \mathrm{ml}$ as the final volume.

By means of the nucleic acid-binding dyes $\mathrm{AO}$ and $\mathrm{PI}$, cell viability was accurately determined. $A O$ is an intercalating stain that can permeate both living and dead cells. AO stains all nucleated cells and generates green fluorescence. PI can only enter dead cells with poor membrane integrity and stains all dead nucleated cells to generate red fluorescence. Groups of cells stained with both $A O$ and PI show all live nucleated cells as fluorescent green and all dead nucleated cells as fluorescent red.

\section{Evaluation of NP-specific markers by qRT-PCR}

The total RNA was isolated using a PureLink RNA Mini Kit. To obtain cDNA, 50 ng of RNA was reverse transcribed with a High-Capacity cDNA Reverse Transcription Kit (Thermo Fisher Scientific, Cat. \# 4368814) using a thermal cycler (ProFlex, Thermo Fisher Scientific).

In each group, the expressions of the NP-specific marker protein chondroadherin (CHAD), which is related to vitality, proliferation, chondrogenic differentiation, and the develop- 

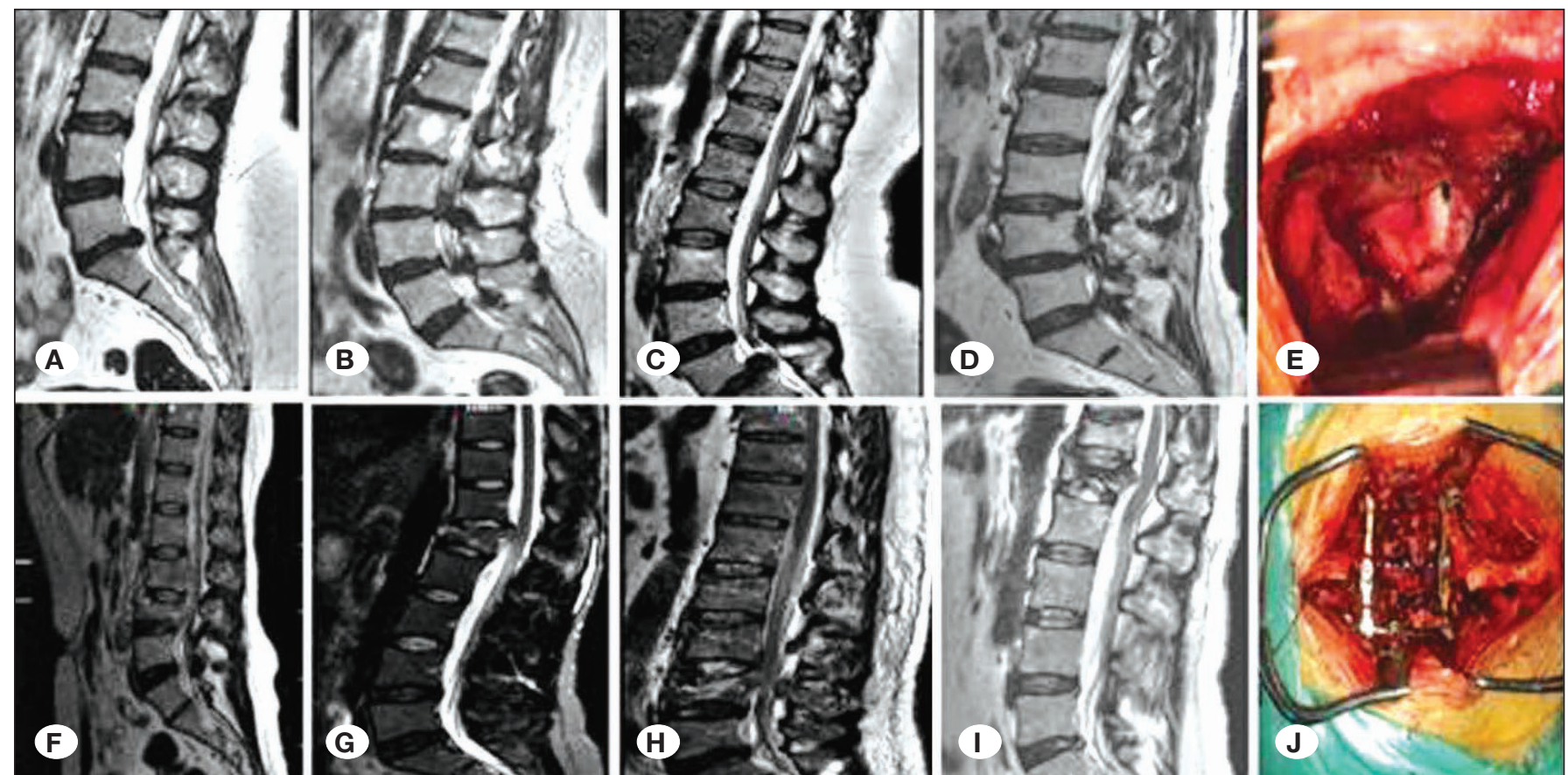

Figure 1: A) T2-weighted sagittal MRI shows L5-S1 subligamentous lumbar disc protrusion. B) T2-weighted sagittal MRI shows L3L4 extruded disc herniation with superior migration. C) T2-weighted sagittal MRI shows L5-S1 intraligamentous extruded lumbar disc herniation. D) T2-weighted sagittal MRI shows L4-L5 sequestrated disc herniation with superior migration. E) Image of herniated fragment compressing the spinal cord during microdiscectomy. F) Supposing that transitional vertebra is S1, T2-weighted sagittal MRI reveals the spinal fracture and healthy L3-L4 intervertebral disc from which NP/AF were obtained. G) T2-weighted sagittal MRI reveals L1 vertebra fracture and healthy L1-L2 intervertebral disc from which NP/AF were obtained. H) T2-weighted sagittal MRI shows L4 vertebra fracture and healthy L3-L4 intervertebral disc from which NP/AF were obtained. I) T2-weighted sagittal MRI shows L1 vertebra fracture and healthy L1-L2 intervertebral disc from which NP/AF were obtained. J) Macro images from the operation of stabilization and laminectomy for spinal fracture during which AF/NP tissues were obtained.

ment of the spinal cord and dorsal colon $(8,41)$, collagen type II (COL2A1) in the extracellular matrix (55), and hypoxia inducible factor-1 alpha (HIF-1a) (9), were evaluated by comparison through a quantitative reverse transcription polymerase chain reaction (qRT-PCR). The data were statistically evaluated.

All genes were amplified using the TaqMan Gene Expression Assay for CHAD (Hs00154382_m1, Cat. \# 4448892), HIF-1a (Hs00153153_m1, Cat. \# 4453320), COL2A1 (Hs00264051_ m1, Cat. \# 4453320) and the internal control gene ACTB (Hs99999903_m1, Cat. \# 4453320). The qRT-PCR reaction mix was prepared with $1 \mathrm{ml}$ of the TaqMan Gene Expression Assay, $10 \mathrm{ml}$ of the TaqMan Gene Expression Master Mix (Cat. \# 4369016), $4 \mathrm{ml}$ of cDNA template, and $5 \mathrm{ml}$ UltraPure DNase/ RNase-Free Distilled Water (Cat. \# 10977035) in MicroAmp Fast Optical 96-Well Reaction Plates (Cat. \#4346906).

The thermocycling conditions were as follows: 2 minutes at $50^{\circ} \mathrm{C}, 10$ minutes at $95^{\circ} \mathrm{C}, 15$ seconds at $95^{\circ} \mathrm{C}$ and 1 minute at $60^{\circ} \mathrm{C}$, for 40 cycles using Applied Biosystems $7300 / 7500$ qRT-PCR system. The RQ values obtained from this RT-qPCR experiment for each sample using the 7500 Fast-SDS program V.2.3 (Thermo Fisher Scientific, Inc.).

\section{Statistical Analyses}

Statistical analyses were performed with the SPSS 18.0 statistics program. The data were provided as means and standard deviations. It was concluded that a two-factor (time and group factors), repeated measures analysis of variance (ANOVA) should be used. The appropriate conditions were examined in order to carry out the tests. The covariance equalization was tested using Box's $M$ test. The equalization of variances for time measurements was examined by Levene's test. It was concluded that the variance-covariance equalization could not be sustained as the results of the tests had a $p$ value $<0.05$. As variance-covariance equalization is required for two-factor, repeated measures ANOVA, if this equivalence is not provided, the ANOVA cannot be performed. For this reason, each factor had to be tested one by one instead of being tested together.

For each factor, a one-factor, repeated measures ANOVA test was performed. Then, the results of this test were put into Mauchly's sphericity test, which determined what $p$ value would be used. For the groups whose test results were found to have a $p$ value $<0.05$, the results were considered to be on the Greenhouse-Geisser line, while the results were considered to be on the assumed sphericity line in the groups whose test results had a $\mathrm{p}$ value $<0.05$ (Table II).

In the groups whose ANOVA test results were found to be significant, post hoc paired comparisons were performed with 
the Bonferroni correction. In each instance of measurement (i.e., on $1^{\text {st }}, 7^{\text {th }}$, and $21^{\text {st }}$ days), the workgroups were tested. In addition, the independent groups were tested by a one-way ANOVA. Because the variances were not homogeneous (the result of Levene's test had a $p<0.05$ ), Tamhane's T2 test was used for post hoc paired comparison. The probability value of $p<0.05$ was found to be significant.

\section{RESULTS}

\section{Release Pharmacokinetics of the Polymeric Scaffold and Physicochemical Properties}

GFs that were loaded on the designed scaffold were accepted for release in a constant and controlled manner (Figure 2).

According to the principle of biodegradation and osmosis, the design was demonstrated to have undergone diffusion (6), which was in accordance with Fick's laws. Furthermore, it was found that the GFs were released into the environment in a controlled manner.

\section{Morphological Evaluation of Cultures}

The cell morphology was evaluated on the $0^{\text {th }}, 7^{\text {th }}$, and $21^{\text {st }}$ days after the GFs were applied on the AFC/NPC cultures. The obtained micrographs are presented in Figure 3.

It was observed that as the application time increased, the number of cells increased. However, it was also observed that in groups 5 and 6 , where the GFs were applied in the presence of hydrogel, the number of cells increased in the extracellular matrix.

Viability and proliferation were also assessed by AO/PI staining in addition to MTT analysis in the same cultures. Micrographs obtained after AO/PI staining are presented in Figure 4. It was observed that cells retained their specific morphology and continued to proliferate in all experimental groups (Figure 4).

\section{Evaluation of Proliferation}

When the post hoc Bonferroni correction test results were evaluated in terms of measurement time, it was found that the

Table II: Results of Mauchly's Sphericity Test for Each Group

\begin{tabular}{lcll}
\hline Groups & $\begin{array}{c}\text { Mauchly's } \\
\text { sphericity } \\
\text { test }\end{array}$ & The preferred p value & Results \\
\hline Group 1 & $\mathrm{p}=0.006$ & Greenhouse-Geisser & $\mathrm{p}<0.05$ \\
\hline Group 2 & $\mathrm{p}=0.001$ & Greenhouse-Geisser & $\mathrm{p}<0.05$ \\
\hline Group 3 & $\mathrm{p}=0.015$ & Greenhouse-Geisser & $\mathrm{p}<0.05$ \\
\hline Group 4 & $\mathrm{p}=0.000$ & Greenhouse-Geisser & $\mathrm{p}<0.05$ \\
\hline Group 5 & $\mathrm{p}=0.011$ & Greenhouse-Geisser & $\mathrm{p}<0.05$ \\
\hline Group 6 & $\mathrm{p}=0.000$ & Greenhouse-Geisser & $\mathrm{p}<0.05$ \\
\hline Group 7 & $\mathrm{p}=0.305$ & Sphericity assumed & $\mathrm{p}<0.05$ \\
\hline Group 8 & $\mathrm{p}=0.354$ & Sphericity assumed & $\mathrm{p}<0.05$ \\
\hline & & &
\end{tabular}

three measurements were significant $(\mathrm{p}<0.05)$. Regarding the results of the one-way ANOVA analysis, there were significant differences in the measurements that were carried out on the three different days: on the $1^{\text {st }}$ day, $F=4,308$ and $p<0.05$; on the $7^{\text {th }}$ day, $F=13,348,566$ and $p<0.05$; and on the $21^{\text {st }}$ day, $F=93,695$ and $p<0.05$.

Afterward, since the result of Levene's test showed a $p$ value $<0.05$ on the $1^{\text {st }}, 7^{\text {th }}$, and $21^{\text {st }}$ days, Tamphane's T2 test was used as a post hoc dual test. The test showed that there were significant differences on the $1^{\text {st }}$ day between the $6^{\text {th }}$ and $8^{\text {th }}$ groups $(p=0.048)$, the $7^{\text {th }}$ and $8^{\text {th }}$ groups $(p=0.000)$, and the $5^{\text {th }}$ and $7^{\text {th }}$ groups $(p=0.04)$. However, there were no significant differences across the groups on the $1^{\text {st }}$ day $(p>0.05)$. According to the comparisons performed on the $7^{\text {th }}$ day, there was a significant difference between the groups with hydrogel and the groups without hydrogel $(p<0.05)$, but there were no significant differences between the groups without hydrogel $(p>0.05)$. The data obtained from the $21^{\text {st }}$ day showed a similarity to the data from the $7^{\text {th }}$ day. It was found that both the experimental and control groups with hydrogel, in which the GFs underwent a controlled release into the environment, had more proliferative cells $(p<0.05)$.

\section{Evaluation of CHAD, HIF-1a, and COL2A1 using qRT-PCR}

Group $1 \mathrm{~A}$ was the reference sample, and CHAD, HIF-1a, and COL2A1 gene expressions were accepted to be 1 (relative quantification $[R Q]=1$ ). Gene expressions in all the other experimental groups were calculated by comparison with the endogenous gene ACTB and the reference sample, resulting in the $R Q$ values in Table III.

COL2A1 expression was not found in any experimental groups. All experimental groups had HIF-1a expression. Moreover, it was found that as expression increased, the application time had increased in all groups. GFs increased 97.05 times when they were applied together with hydrogel with GFs, especially in intact tissue. CHAD expression increased timedependently. In group 2, gene expression decreased on the $7^{\text {th }}$ day when compared to the $0^{\text {th }}$ hour. However, it increased 8.31 times when compared to the $21^{\text {st }}$ day. In groups 3 and 4, CHAD expression was not seen at the $0^{\text {th }}$ hour, yet it increased on the $7^{\text {th }}$ and $21^{\text {st }}$ days. CHAD expression was not seen on the $21^{\text {st }}$ day in group 5. CHAD expression was not found in group 6, in which GFs were applied to intact tissue by hydrogel. Group 7, in which hydrogel was applied but not GFs, exhibited CHAD expression at the $0^{\text {th }}$ hour and on the $21^{\text {st }}$ day. CHAD expression was only seen on the $21^{\text {st }}$ day in group 8 . The results of vitality, toxicity, and proliferation tests showed that HIF-1a and CHAD expressions increased only in the culture plates with hydrogel on the $21^{\text {st }}$ day.

\section{DISCUSSION}

Lumbar pain is known as one of the most frequent causes of disability. It is a primary health problem that causes serious economic costs and reduces the work force (44). In IVD, NPC/ AFC degenerations are the primary causes (26). In severe lumbar pain, which develops due to IVD degeneration, facets and/ or epidural injections may be applied for symptomatic treat- 


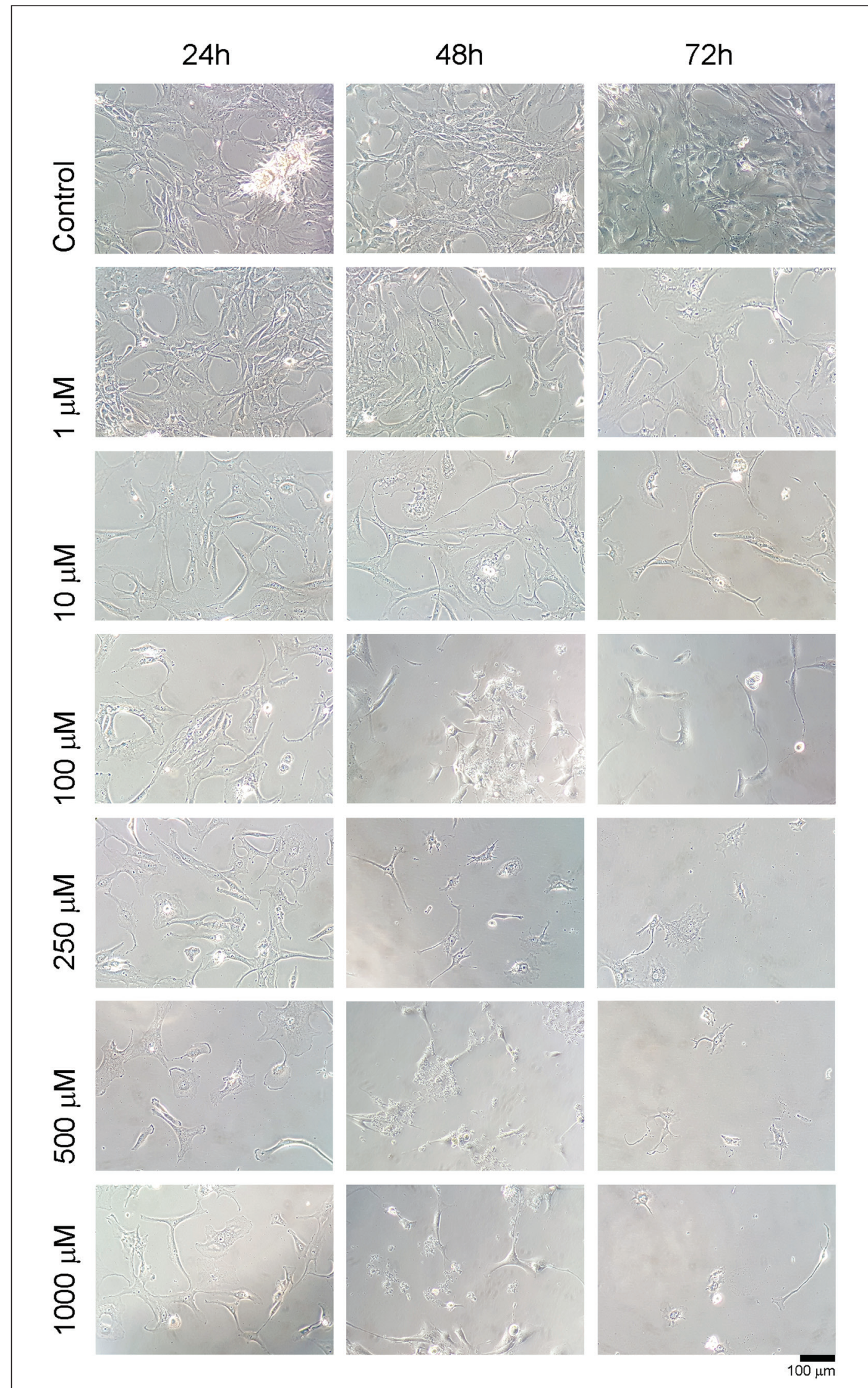

Figure 2: Graph of physicochemical parameters of the designed polymeric scaffold. 


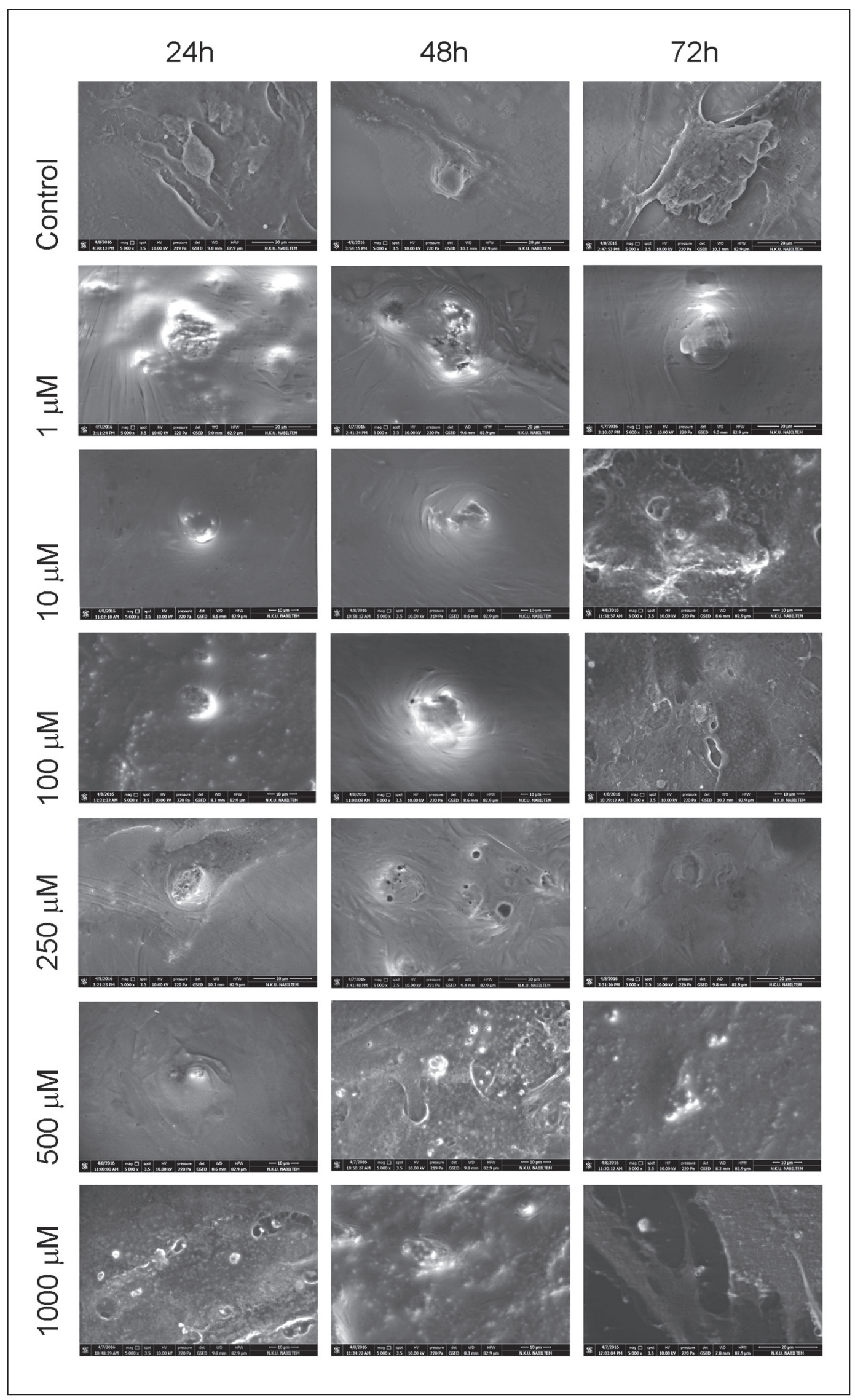

Figure 3: Inverted light microscopic images. 


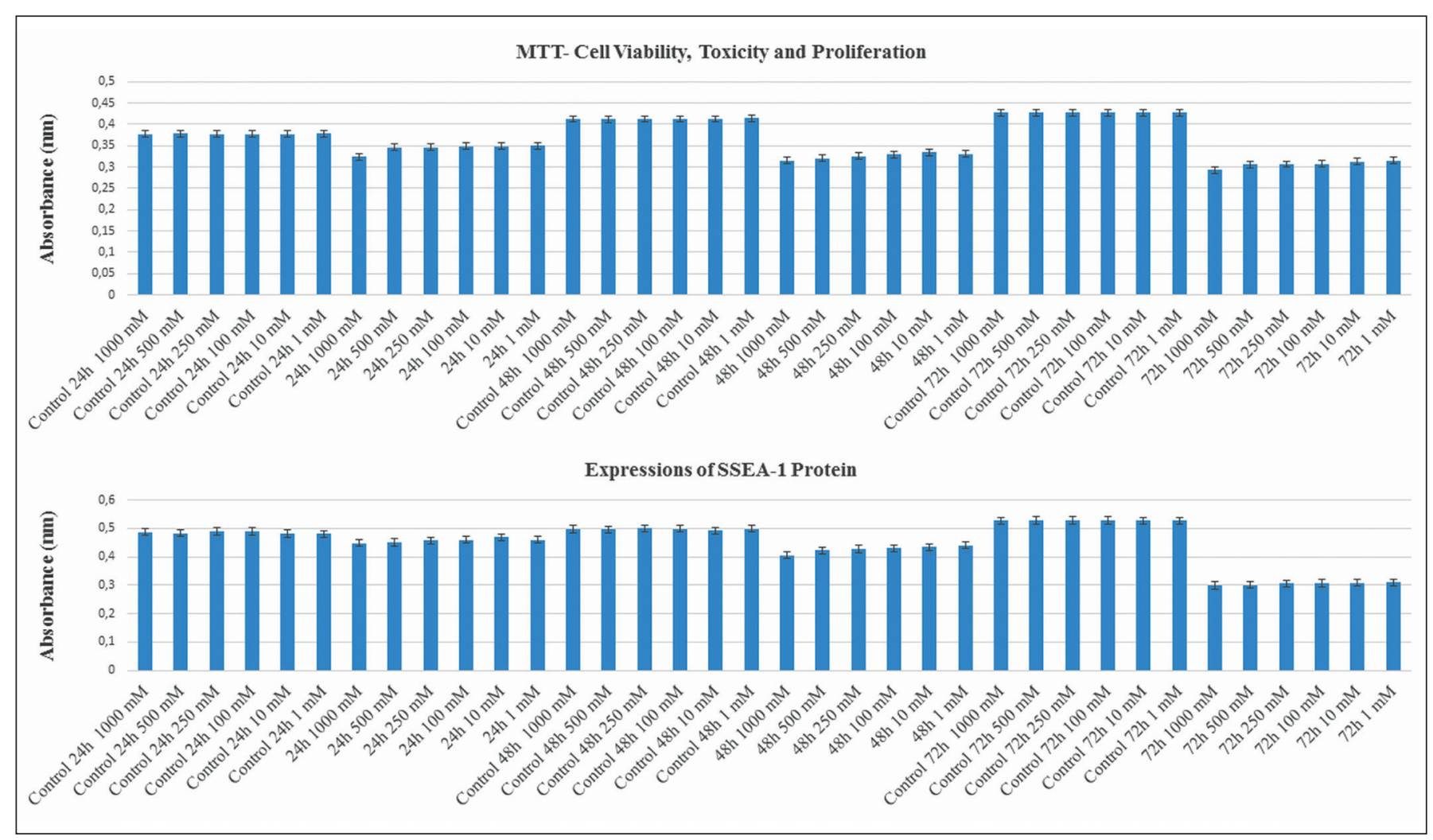

Figure 4: AO/PI staining.

ment. Simple microdiscectomy and/or fusion surgery may be administered in lumbar disc hernias and segmental instabilities that occur after IVD degeneration $(4,26,29,32,36,39)$.

Disc degeneration is a complicated process that occurs following an imbalance between anabolic and catabolic processes. As known from the molecular studies that have been carried out so far, deregulation of numerous signaling pathways is responsible for the degeneration of NPCs (50).

Apart from surgical modalities, developments in regenerative medicine studies have been increasing. In these studies, the aim is to repair and stop damage to NP/AF tissues at the cellular scale by imbuing them with hydrogels.

In the spinal disc degeneration process, it is known that proteoglycan-rich gel structures lose glucose aminoglycan. As a result, the biomechanics of the vertebrae are negatively affected. Therefore, minimally invasive methods are required to regain the physiological mechanics of vertebrae $(8,26,32)$.

Cell-based treatments may be applied through invasive methods in early periods of disc degeneration. However, in order to apply these methods, appropriate and healthy proliferative cells are needed. Currently, scaffolds containing GFs are being studied for use in the treatment of degenerative IVD $(4,9,15,16,29,31,32,36,53)$. It can be concluded that cell-based studies and studies concerning pharmaceutical technology are popular.

BMPs are members of the transforming growth factor- $\beta$ (TGF- $\beta$ ) superfamily, acting as potent regulators during embryogenesis and bone and cartilage formation and repair. Cell and molecular biology approaches have revealed the great complexity of BMP action, which has subsequently been confirmed by transgenic animal studies. There is evidence that BMPs, as members of the TGF- $\beta$ superfamily, are initially identified as osteoinductive cytokines that promote bone and cartilage formation in vivo (23), or that they play a role in metastatic progression and tumorigenesis of BMPs (54).

However, it should not be forgotten that in the present research, GFs were not applied in systemic circulation with direct injections, as in conventional applications. The peptide structural substance was applied by locking it into a controlled release drug delivery system. More importantly, thanks to the "selective targeting of anti-tumor agents" studies, which aim to reduce the present toxicity of pharmaceutical preparations that can damage tissues and increase tumor activity, contemporary cancer chemotherapies have gained momentum (31). Because cancer drugs, when given directly to the body, can destroy non-damaged cells as well as damaged cells. For this reason, intensive studies have concentrated on controlled release systems to ensure that the pharmaceuticals can be activated directly on the targeted site (49).

Balkovec et al. reported that loss in disc height might have mechanical effects, although the direct effect of degeneration as a result of disc height loss on vertebrae kinematics is not known. They used 20 pig vertebrae in their research and reported needing minimally invasive treatment methods to gain disc height (4). They emphasized that injectable hydrogels 
Table III: $R Q$ Values Obtained from qRT-PCR Experiments of CHAD, HIF-1a, and COL2A1 Genes

\begin{tabular}{|c|c|c|c|c|}
\hline Group ID & & CHAD $^{a}$ & HIF-1 $a^{a}$ & $\mathrm{COL}_{2 A} 1^{\mathrm{a}}$ \\
\hline & A & 1 & 1 & - \\
\hline \multirow[t]{3}{*}{ Group 1} & $B$ & 2.11 & 1.53 & - \\
\hline & $\mathrm{C}$ & 4.68 & 12.36 & - \\
\hline & $A$ & 4.19 & 0.95 & - \\
\hline \multirow[t]{3}{*}{ Group 2} & $B$ & 3.11 & 1.34 & - \\
\hline & $\mathrm{C}$ & 8.31 & 20.34 & - \\
\hline & A & - & 0.97 & - \\
\hline \multirow[t]{3}{*}{ Group 3} & $\mathrm{~B}$ & 0.42 & 1.3 & - \\
\hline & C & 8.38 & 12.08 & - \\
\hline & A & - & 1.03 & - \\
\hline \multirow[t]{3}{*}{ Group 4} & B & 1.34 & 1.78 & - \\
\hline & C & 7.54 & 20.06 & - \\
\hline & A & 4.73 & 1.41 & - \\
\hline \multirow[t]{3}{*}{ Group 5} & $\mathrm{~B}$ & - & 5.44 & - \\
\hline & $\mathrm{C}$ & - & 5.90 & - \\
\hline & $A$ & - & 0.94 & - \\
\hline \multirow[t]{3}{*}{ Group 6} & $\mathrm{~B}$ & - & 7.94 & - \\
\hline & $\mathrm{C}$ & - & 97.05 & - \\
\hline & $A$ & 1.34 & 2.5 & - \\
\hline \multirow[t]{3}{*}{ Group 7} & $\mathrm{~B}$ & - & 18.37 & - \\
\hline & $\mathrm{C}$ & 13.13 & 11.40 & - \\
\hline & A & - & 1.58 & - \\
\hline \multirow[t]{2}{*}{ Group 8} & $\mathrm{~B}$ & - & 1.59 & - \\
\hline & C & 8.53 & 9.00 & - \\
\hline
\end{tabular}

aCHAD: chondroadherin. HIF-1a: hypoxia-inducible factor 1-alpha. COL2A1: collagen, type II, alpha 1. "_"symbol: no gene expression defined.

might be appropriate in IVD treatment. After the application of hydrogels, they indicated that relative angular shifting decreased by $13.8 \%$ in the superior segment and $4.5 \%$ in the inferior segment. Furthermore, they noted that hydrogel injection resulted in an improvement of $12.7 \%$ in the superior segment and $6.4 \%$ in the inferior segment. Based on these findings, they underlined that drug delivery systems as well as hydrogels might be a treatment method in which degenerated IVD kinematics are restored (4).

Ehlicke et al. cultured their polymeric scaffolds, which they designed to treat NP degeneration using mesenchymal stem cells by means of a 3D methodology, for 21 days (8). They used SYBR Green/propidium iodide double staining to determine apoptosis, and a WST-1 assay to determine proliferation with the purpose of evaluating cell survival and development. They used CHAD and cytokeratin-19 markers, which are NP-specific marker proteins, for fluorescent immunostaining to demonstrate differentiation from mesenchymal stem cells to NPCs with the help of GFs added to the medium. They showed that vital and proliferative capacity can be preserved during culturing. They also demonstrated through an immunofluorescence method that IGF-1, fibroblast growth factor 2, and platelet-derived growth factor BB provided for the differentiation of mesenchymal stem cells to NPC. However, they reported that transforming growth factor beta 3 did not show this kind of effect (8).

Kumar et al. evaluated the differentiation of mesenchymal stem cells to NPC by using pHEMA-co-APMA grafted with PAA. However, they also included mechanical effects in their study. They surveyed SOX-9, aggrecan, and COL2A1, which are matrix markers. They indicated that a minimally invasive apparatus was required to transmit the system to the required area (26).

Miles et al. studied the compressive stiffness of hydrogels in an ex vivo model (32). They aimed to show that the mechanics in hydrogel, which is an injectable peptide in a soluble glucose aminoglycan structure, could be used to restore the mechanics of denucleated discs. They are eventually transformed into a gel with similar mechanical characteristics to the original tissue, in seconds or minutes when compared to the chosen peptide. Miles et al. asserted that, unlike other biomaterials, polymeric scaffolds that are injected by needles with a 25-gauge diameter could substantially decrease tissue damage. In addition, they maintained that the polymeric tissue might draw water like the original tissue (32).

In another study where GFs were used to increase NPC regeneration, it was concluded that BMP-2 and BMP-7 might be promising for further studies. In this study, NPCs in the caudal discs of cattle were treated with fibrin-hyaluronan hydrogels for 14 days. As a result, they demonstrated that BMP-2/BMP-7 increased COL2A1 gene expression and glucose aminoglycan synthesis by connecting to the heterodimeric hydrogel. However, they emphasized that the osteogenic/fibroblastic effects were observed as a result of COL1A1 or the difference in phosphatase levels in tissues after culturing (29).

Peeters et al. studied BMP-2 and BMP-7-GFs with short half-lives - in the regeneration of NPCs in vivo and in vitro. In addition, they examined BMP-2-embedded homodimers and BMP-7-embedded heterodimers, which allowed for the controlled release of GFs into the environment in order to prevent heterotrophic ossification (39). In goats with degenerated IVD, they tested hydrogels imbued with GFs that had been conjugated with hyaluronic acid. They applied polymeric scaffolds containing BMP-2 and BMP-7 into adult goat lumbar discs in which an ABC enzyme was injected. Goats were scarified for 12 weeks. They radiologically evaluated the discs through MRls with T2 mapping. The side effect of heterotrophic ossification was not present in the goats. They reported disc head loss in the living experimental animals 
following a slight degeneration (39). Although they indicated observing a strong relationship between groups after MRI, biochemical, and histological analyses, there was no statistical significance across groups. In addition, they commented that the reason for the lack of regeneration was the low number of doses and low time limit (39). For this reason, high doses of IGF-1 and BMP-2 were used in the present study.

Paglia et al. examined the in vivo effects of platelet-derived growth factor BB (PDGF-BB), which was embedded into a thiol-modified hyaluronic acid (TMHA) hydrogel, on degenerated IVD (36). They designed a disc degeneration model based on the rabbit annular puncture model. After four weeks of damage, they performed histology and biochemical analyses. They proved that less degeneration occurred in the PDGF-BB-TMHA group as compared to the other groups.

Likhitpanichkul et al. studied a local drug delivery system in the treatment of damaged IVD tissues (30). They reported that these tissues are appropriate systems for IVD treatment since they are avascular-shaped and transport-limited. They prepared genipin cross-linked fibrin with collagen type I hollow spheres (CHS) and loaded it into the system to locally test infliximab, a biological agent with anti-inflammatory characteristics. Because tumor necrosis factor alpha is effective in the release of pro-inflammatory cytokines and pain mediators, they aimed to make use of this characteristic (30). They chose genipin cross-linked fibrin because it is adhesive, degrades slowly, and is injectable. In addition, they claimed that this system can be used to eliminate defects of AF. After low or high doses of infliximab were embedded into the genipin cross-linked fibrin with or without $\mathrm{CHS}$, the researchers examined the kinetic release of these gels. As a result, they reported that genipin cross-linked fibrin could be released continuously, and that a high infliximab release occurred as the dosage was increased. They also indicated that infliximab that had been adhered to $\mathrm{CHS}$ in the genipin cross-linked fibrin was released into the environment only after enzymatic degradation (30). As for the present study's design, the scaffold was observed to diffuse based on osmosis and biodegradation in accordance with Fick's law.

NPCs, which evolve out of the notochord, bring about extracellular matrix synthesis, which provides for the health and mechanical function of the discs. In the literature, it is indicated that NPCs with unique morphology and molecular expression are in the $\mathrm{N}$-cadherin $(\mathrm{CDH} 2)$-positive cell set. However, under degenerative conditions, it has been emphasized that a decrease in the set occurs as a result of morphological changes after $\mathrm{CDH} 2$ expression loss (17).

Hwang et al. aimed to show that CDH2-positive cell sets are healthy and biosynthetically active NPCs; accordingly, they simulated an NP microenvironment using a lamininfunctionalized hydrogel system (17). They showed that the natural phenotype and cell morphology form only in the presence of $\mathrm{CDH} 2$. Furthermore, they inferred that NPCs' phenotypes and biosynthesis are affected after the interaction between $\mathrm{CDH} 2$ and $\beta$-catenin-regulated signaling (17).
Another study evaluated the bioactivities of these peptides in vitro (45). After the most appropriate scaffold for in vivo degradation and tissue reactions were chosen, COL2A1, SOX-9, and aggrecan molecules were analyzed, and it was reported that RAD-SNV and RAD-KPS showed better bioactivity when compared to RADA16-I and RAD-KAI (45).

Recently, a study in which an in-situ, cross-linked, thermoresponsive drug delivery system was examined in a canine model for use in invasive treatments for IVD was performed. Mesenchymal stem cells that were encapsulated in alginate lead were loaded into the prepared macroporus, PGEDAderived microgel (PM). Afterward, the researchers attempted to form injectable hydrogels that were not affected by cell niches. They indicated that PM-powered alginate hydrogels were strong, more elastic than alginates, and encapsulated cells better. They reported that NPCs in 3D cultures contained higher NP markers than in 2D cultures and that mesenchymal stem cell-laden PMs inhibited cell leakage to NP tissue in an ex vivo organ model. They underlined that the survival time of cells could be extended from three months to six months (53).

In the literature, there are a limited number of studies regarding IVD tissue or NP-oriented pharmaceutical studies. Upon reviewing these studies, the authors noticed that they were performed on living mammals or cell cultures obtained from mammals $(7,27,34,36,39,43)$. However, due to the fact that human and animal tissues might be different in their physiological nature and sensitivity, the data obtained from animal tissues might not be reliable in representing the characteristics of human tissue. In similar studies where animal tissues were not used, commercial cell lines were used instead $(11-13,19,21,25,35)$. While designing the present study, no animal tissues or commercial cell lines were used. Instead, primary human NP cell cultures, which were isolated from healthy NP tissues or degenerated NP tissues, were used. Healthy tissues were obtained from patients who had vertebrae structure operations, and degenerated tissues were obtained from patients who had NP excision operations. Thus, both NP cells and other histological structures were analyzed. It is the authors' opinion that the data presented in this paper are significant. Although primary human cell cultures were used, the study comprised an in vitro experimental design.

In order to increase NPC/AFC proliferation, IGF-1 was embedded in the inner layer of the polymeric scaffold, while BMP-2 was embedded in the outer layer. Both apoptosis and proliferation were evaluated. However, unlike Ehlicke et al.(8), proliferation was analyzed by MTT. In addition, CHAD, HIF-1a, and COL2A1 markers were considered, constituting a main strength of the present research. However, one limitation was that only nine cases from the same race were included. Other limitations include the study's lack of biomechanical research and the fact that gene expression varies due to individual differences that are independent from disease.

It is known that a unit of HIF-1a dimerizes with HIF-1 $\beta$ by translocating from the cytoplasm to the nucleus. HIF, which activates by connecting to other co-factors in the cell nucleus, is connected to a specific row on DNA as a hypoxia-response agent. Afterward, the target genes are triggered. The HIF-1a 
bottom unit is degraded by ubiquitination under normoxic conditions. However, its level decreases under low glucose levels, oxidative stress, and hypoxic environments $(3,48)$.

As a result of the present research, it was observed that HIF1 a levels increased in all groups in a time-dependent manner. HIF-1a gene expression was observed to be 97 times higher in cultures prepared with intact tissues than in the control group. There was an increase in cultures where GFs were applied with hydrogel (group 2, $21^{\text {st }}$ day, $R Q=20.34$ ). As for cultures prepared with degenerated tissue, it was found that the increase was higher in the group in which only GFs were used (group $3,21^{\text {st }}$ day, $R Q=12.08$ ) than in the group where cultures were prepared by GFs together with hydrogel (group $5, R Q=5.90)$. It was observed that there was a similar level of HIF-1a $(R Q=12.36)$ in the experimental group (group 1), where GFs were not used in degenerated tissues.

It is known that COL2A1 expression is important in extracellular matrix development (46). Rosenzweig et al. concluded that because human intervertebral disc cells expand independently from acute hernias, they produce less collagen type II, aggrecan genes, CHAD genes, and protein than standard cultures (41). In the present study, COL2A1 expression was evaluated, as it represents similar tissues. However, surprisingly, COL2A1 expression did not occur.

As for CHAD expression, it was observed to increase timedependently in group 1 . While gene expression decreased at the $0^{\text {th }}$ hour, it increased 8.31 times on the $21^{\text {st }}$ day in group 2 . There was no CHAD expression at the $0^{\text {th }}$ hour, yet there was an increase on the $7^{\text {th }}$ and $21^{\text {st }}$ days in groups 3 and 4 . In group 6 , CHAD expression was observed at the $0^{\text {th }}$ hour, whereas it was not observed on the $7^{\text {th }}$ and $21^{\text {st }}$ days. GFs together with hydrogels were applied in intact tissue in group 6.

Hydrogel, but not GFs, was applied in group 7. CHAD expression was observed at the $0^{\text {th }}$ hour and on the $21^{\text {st }}$ day in this group. As for group 8, CHAD expression was seen on the $21^{\text {st }}$ day. Although an increase in CHAD expression was seen in relation to application time, the increase does not seem to be related to the hydrogel application.

In order to decide whether degenerated NP cells were regenerating, CHAD, HIF-1a, COL2A1 gene expression levels were evaluated on the molecular level by qRT-PCR. It was observed that CHAD expression increased as the application time increased in degenerated and healthy cell cultures in which polymeric scaffolds had been implemented to allow sequential and controlled release. In addition, it was found that when GFs were applied together with hydrogel, increases in HIF-1a gene expression were positively affected. In addition, in the experimental groups, it was discovered that when GFs were applied together with hydrogel, it increased proliferation, produced more living cells, and resulted in more morphological extracellular matrix development, which is crucial for cell integrity.

Scientists conducting research in the field of genetic engineering and pharmaceutical technology for neurosurgery have focused on preparations that allow large quantities of BMP production for clinical use. However, it has been empha- sized that a drug delivery system, such as type I collagen and calcium phosphate ceramics, is needed in order to prevent systemic circulation of the GFs from the site where they are being applied, to provide controlled release into their environment, and to maximize biological activity in the surgical field. Clinical trials have demonstrated the benefits of recombinant human BMPs (rhBMPs) - such as BMP-2 and BMP-7-approved by the American Food and Drug Administration (FDA). However, adverse effects due to possibly high BMP dosage, such as swelling, seroma, and increased risk of cancer, have been reported. Furthermore, it has been stressed that their clinical use should incorporate a research design comprising well-designed, randomized, and double-blind clinical trials. It is clear that the molecular structure of growth hormones such as BMP, pharmacological mechanisms of action, and the critical data of possible clinical applications should be assessed effectively in contemporary research, in which non-label applications along with strong evidence for the reliability and efficacy of rhBMPs have increased (5).

\section{- CONCLUSION}

The scaffold developed in this study is appropriate for surgical techniques that may encounter defects of AF/NP tissues. It was reported to lead to partial biomechanical restoration in vitro. However, a design in which animal tissues are used should be developed for this technique to be used in surgery.

\section{ACKNOWLEDGEMENT}

We are thankful to Dr. Bahar HACIOGLU KASIM from Yasam Hospital, Department of Radiology, Turkey, for her help in evaluating the radiological images.

\section{- REFERENCES}

1. An HS, Masuda K, Inoue N: Intervertebral disc degeneration: Biological and biomechanical factors. J Orthop Sci 11(5):541552, 2006

2. Bach FC, Miranda-Bedate A, van Heel FW: Bone morphogenetic protein-2, but not mesenchymal stromal cells, exert regenerative effects on canine and human nucleus pulposus cells. Tissue Eng Part A 23(5-6):233-242, 2017

3. Bai $R$, Zhao $A Q$, Zhao ZQ, Liu WL, Jian DM: MicroRNA-195 induced apoptosis in hypoxic chondrocytes by targeting hypoxia-inducible factor 1 alpha. Eur Rev Med Pharmacol Sci 19(4):545-551, 2015

4. Balkovec C, Vernengo AJ, McGill SM: Disc height loss and restoration via injectable hydrogel influences adjacent segment mechanics in-vitro. Clin Biomech 36:1-7, 2016

5. Carreira AC, Lojudice FH, Halcsik E, Navarro RD, Sogayar MC, Granjeiro JM: Bone morphogenetic proteins: Facts, challenges, and future perspectives. J Dent Res 93(4):335345, 2014

6. Ciftci Z, Deniz M, Yilmaz I, Ciftci HG, Sirin DY, Gultekin E: In vitro analysis of a novel controlled release system designed for intratympanic administration of $\mathrm{N}$-acetylcysteine: $\mathrm{A}$ preliminary report. Am J Otolaryngol 36(6):786-793, 2015 
7. Duff RS, Langtimm CJ, Richardson MK, Sieber-Blum M: In vitro clonal analysis of progenitor cell patterns in dorsal root and sympathetic ganglia of the quail embryo. Dev Biol 147(2):451-459, 1991

8. Ehlicke F, Freimark D, Heil B, Dorresteijn A, Czermak $P$ : Intervertebral disc regeneration: Influence of GFs on differentiation of human mesenchymal stem cells (hMSC). Int J Artif Organs 33(4):244-252, 2010

9. Feng $\mathrm{G}$, Jin $\mathrm{X}, \mathrm{Hu} \mathrm{J}$ : Effects of hypoxias and scaffold architecture on rabbit mesenchymal stem cell differentiation towards a nucleus pulposus-like phenotype. Biomaterials 32(32):8182-8189, 2011

10. Gibson JN, Waddell G: Surgery for degenerative lumbar spondylosis: Updated Cochrane review. Spine 30(20):23122320, 2005

11. Gumustas F, Yilmaz I, Sirin DY: Chondrocyte proliferation, viability, and differentiation is declined following administration of methylphenidate utilized for the treatment of attention deficit/hyperactivity disorder. Hum Exp Toxicol 36(9):981-992, 2017

12. Gumustas SA, Yilmaz I, Isyar M, Sirin DY, Batmaz AG, Ugras AA, Oznam K, Ciftci Z, Mahirogullari M: Assessing the negative impact of phenyl alkanoic acid derivative, a frequently prescribed drug for the suppression of pain and inflammation, on the differentiation and proliferation of chondrocytes. J Orthop Surg Res 11(1):70, 2016

13. Guzelant AY, Isyar M, Yilmaz I, Sirin DY, Cakmak S, Mahirogullari M: Are chondrocytes damaged when rheumatologic inflammation is suppressed? Drug Chem Toxicol 40(1):13-23, 2017

14. Hanley EN Jr, McCulloch JA: Surgical Indication and Techniques International Society for the Study of the Lumbar Spine: The Lumbar Spine. 2nd ed. Philadelphia, PA: WB Saunders, 1996:492-524

15. Henry N, Clouet J, Fragale A: Pullulan microbeads/Si-HPMC hydrogel injectable system for the sustained delivery of GDF-5 and TGF- $\beta 1$ : New insight into intervertebral disc regenerative medicine. Drug Deliv 24(1):999-1010, 2017

16. Hu B, Wang J, Wu X, Chen Y, Yuan W, Chen H: Interleukin-17 upregulates vascular endothelial growth factor by activating the JAK/STAT pathway in nucleus pulposus cells. Joint Bone Spine 84(3):327-334, 2017

17. Hwang PY, Jing L, Chen J: N-cadherin is key to expression of the nucleus pulposus cell phenotype under selective substrate culture conditions. Sci Rep 6:28038, 2016

18. Inoue N, Orías AAE: Biomechanics of intervertebral disk degeneration. Orthop Clin North Am 42(4):487-499, 2011

19. Isyar M, Bilir B, Yilmaz I: Are biological agents toxic to human chondrocytes and osteocytes? J Orthop Surg Res 10(1):118, 2015

20. Isyar M, Gumustas SA, Yilmaz I, Sirin DY, Tosun HB, Mahirogullari $\mathrm{M}$ : Are we economically efficient enough to increase the potential of in vitro proliferation of osteoblasts by means of pharmacochemical agents? Open Orthop J 10:420430, 2016

21. Isyar M, Yilmaz I, Sirin DY, Yalcin S, Guler O, Mahirogullari M: A practical way to prepare primer human chondrocyte culture. J Orthop 13(3):162-167, 2016
22. Jaumard NV, Welch WC, Winkelstein BA: Spinal facet joint biomechanics and mechanotransduction in normal, injury and degenerative conditions. J Biomech Eng 133(7):071010, 2011

23. Kang MH, Kim JS, Seo JE, Oh SC, Yoo YA: BMP2 accelerates the motility and invasiveness of gastric cancer cells via activation of the phosphatidylinositol 3-kinase (PI3K)/Akt pathway. Exp Cell Res 316(1):24-37, 2010

24. Koes BW, van Tulder MW, Thomas S: Diagnosis and treatment of low back pain. BMJ 332(7555):1430-1434, 2006

25. Komur B, Akyuva Y, Karaslan N, Isyar M, Gumustas SA, Yılmaz I, Akkaya S, Sirin DY, Mutlu CA, Batmaz AG, Guler O, Mahirogullari $\mathrm{M}$ : Can a biodegradable implanted bilayered drug delivery system loaded with BMP-2/BMP-12 take an effective role in the biological repair process of bone-tendon injuries? A preliminary report. J Pharm (Cairo) 2017:7457865, 2017

26. Kumar D, Lyness A, Gerges I, Lenardi C, Forsyth NR, Liu Y: Stem cell delivery with polymer hydrogel for treatment of intervertebral disc degeneration: From 3D culture to design of the delivery device for minimally invasive therapy. Cell Transplant 25(12):2213-2220, 2017

27. Li P, Gan Y, Wang H: Dynamic compression effects on immature nucleus pulposus: A study using a novel intelligent and mechanically active bioreactor. Int J Med Sci 13(3):225234, 2016

28. Li X, Dou Q, Kong Q: Repair and regenerative therapies of the annulus fibrosus of the intervertebral disc. J Coll Physicians Surg Pak 26(2):138-144, 2016

29. Li Z, Lang G, Karfeld-Sulzer LS: Heterodimeric BMP-2/7 for nucleus pulposus regeneration-In vitro and ex vivo studies. J Orthop Res 35(1):51-60, 2017

30. Likhitpanichkul M, Kim Y, Torre OM: Fibrin-genipin annulus fibrosus sealant as a delivery system for anti-TNFa drug. Spine J 15(9):2045-2054, 2015

31. Lin W, Zhang X, Qian L, Yao N, Pan Y, Zhang L: Doxorubicinloaded unimolecular micelle-stabilized gold nanoparticles as a theranostic nanoplatform for tumor-targeted chemotherapy and computed tomography imaging. Biomacromolecules 18(12):3869-3880, 2017

32. Miles DE, Mitchell EA, Kapur E, Beales PA, Wilcox RK: Peptide: Glycosaminoglycan hybrid hydrogels as an injectable intervention for spinal disc degeneration. J Mater Chem B Mater Biol Med 4(19):3225-3231, 2016

33. Moore RJ: The vertebral endplate: Disc degeneration, disc regeneration. Eur Spine J 15(3):333-337, 2006

34. Oudega M, Marani E, Thomeer RT: Transient expression of stage-specific embryonic antigen-1 (CD15) in the developing dorsal rat spinal cord. Histochem J 24(11):869-877, 1992

35. Oznam K, Sirin DY, Yilmaz I, Kaya YE, Isyar M, Gumustas SA: lopromide- and gadopentetic acid-derived preparates used in MR arthrography may be harmful to chondrocytes. J Orthop Surg Res 12(1):98, 2017

36. Paglia DN, Singh H, Karukonda T, Drissi H, Moss IL: PDGFBB delays degeneration of the intervertebral discs in a rabbit preclinical model. Spine 41(8):449-458, 2016 
37. Pao JL, Chen WC, Chang CH, Chen S, Wang JL: Clinical significance of post decompression facet joint effusion after minimally invasive decompression for degenerative lumbar spinal stenosis. J Spinal Disord Tech 27(8):318-323, 2014

38. Pearce J, Moll JMH: Conservative treatment and natural history of acute lumbar disc lesions. J Neurol Neurosurg Psychiat 30(1):13-17, 1967

39. Peeters M, Detiger SE, Karfeld-Sulzer LS: BMP-2 and BMP2/7 heterodimers conjugated to a fibrin/hyaluronic acid hydrogel in a large animal model of mild intervertebral disc degeneration. BioRes Open Access 4(1):398-406, 2015

40. Pratsinis H, Kletsas D: Organotypic cultures of intervertebral disc cells: Responses to GFs and signaling pathways involved. Biomed Res Int Article ID: 427138, 2015

41. Rosenzweig DH, Tremblay Gravel J, Bisson D, Ouellet JA, Weber $\mathrm{MH}$, Haglund L: Comparative analysis in continuous expansion of bovine and human primary nucleus pulposus cells for tissue repair applications. Eur Cell Mater 33:240-251, 2017

42. Saal JA, Saal JS: Nonoperative treatment of herniated lumbar intervertebral disc with radiculopathy: An outcome study. Spine 14(4):431-437, 1976

43. Sieber-Blum M: SSEA-1 is a specific marker for the spinal sensory neuron lineage in the quail embryo and in neural crest cell cultures. Dev Biol 134(2):362-375, 1989

44. Takura T, Yoshimatsu M, Sugimori H: Cost-Effectiveness analysis of percutaneous vertebroplasty for osteoporotic compression fractures. Clin Spine Surg 30(3):205-210, 2017

45. Tao H, Wu Y, Li H: BMP7-based functionalized self-assembling peptides for nucleus pulposus tissue engineering. ACS Appl Mater Interfaces 7(31):17076-17087, 2015

46. Tillgren V, Ho JC, Önnerfjord P, Kalamajski S: The novel small leucine-rich protein chondroadherin-like (CHADL) is expressed in cartilage and modulates chondrocyte differentiation. J Biol Chem 290(2):918-925, 2015
47. Urban JP, Roberts S: Degeneration of the intervertebral disc. Arthritis Res Ther 5(3):120-130, 2013

48. Wang P, Zhang F, He Q, Wang J, Shiu HT, Shu Y, Tsang WP, Liang S, Zhao K, Wan C: Flavonoid compound icariin activates hypoxia inducible factor-1a in chondrocytes and promotes articular cartilage repair. PLoS One 11(2):e0148372, 2016

49. Wang TW, Yeh CW, Kuan CH, Wang LW, Chen LH, Wu $\mathrm{HC}$, Sun JS: Tailored design of multifunctional and programmable $\mathrm{pH}$-responsive self-assembling polypeptides as drug delivery nanocarrier for cancer therapy. Acta Biomater 58:54-66, 2017

50. Wang Z, Fu C, Chen Y: FoxC2 enhances BMP7-mediated anabolism in nucleus pulposus cells of the intervertebral disc. PloS One 11(1):0147764, 2016

51. Yilmaz I, Akkaya S, Isyar M: Is there a treatment protocol in which platelet-rich plasma is effective? J Orthop 13(4):316321, 2016

52. Yilmaz I, Gokay NS, Gokce A, Tonbul M, Gokce C: A novel designed chitosan based hydrogel which is capable of consecutively controlled release of TGF-Beta 1 and BMP-7. J Med Sci 33(1):18-32, 2013

53. Zeng Y, Chen C, Liu W: Injectable microcryogels reinforced alginate encapsulation of mesenchymal stromal cells for leakproof delivery and alleviation of canine disc degeneration. Biomaterials 59:53-65, 2015

54. Zhang G, Huang P, Chen A, He W, Li Z, Liu G, Wang J: How BMP-2 induces EMT and breast cancer stemness through $\mathrm{Rb}$ and CD44? Cell Death Dis 9(2):20, 2018

55. Zhou X, Tao Y, Liang C, Zhang Y, Li H, Chen Q: BMP3 alone and together with TGF- $\beta$ promote the differentiation of human mesenchymal stem cells into a nucleus pulposus-like phenotype. Int J Mol Sci 16(9):20344-20359, 2015 